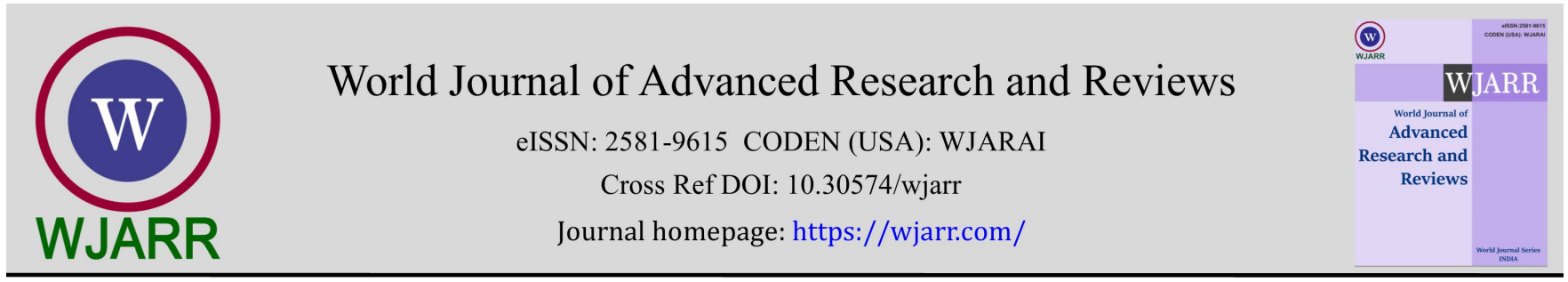

(REVIEW ARTICLE)

Check for updates

\title{
Recovery of base and precious metals from PCBs (Printed Circuit Boards) in waste electrical and electronic equipment (WEEE)
}

\author{
Yete Pélagie 1, 2, *, Togbe FC Alexis 1, Yovo Franck 1, Suanon Fidèle 1, Sidohounde Assou 1, 2, Kouwanou Cosme 1, 2 \\ Wekpon Honorat ${ }^{1}$, Ahlonsou Daniel ${ }^{1}$, Wotto Valentin ${ }^{1,2}$ and Sohounhloue Dominique ${ }^{2}$

\begin{abstract}
${ }^{1}$ Laboratory of Physical Chemistry-Materials and Molecular Modeling, Department of Chemistry, Faculty of Science and Technology, University of Abomey-Calavi, Abomey-Calavi, Benin.

${ }^{2}$ Laboratory of Study and Research in Applied Chemistry, Department of Chemical Process Engineering, Polytechnic School of Abomey-Calavi, University of Abomey-Calavi, Abomey-Calavi, Benin.
\end{abstract}

World Journal of Advanced Research and Reviews, 2022, 13(01), 001-011

Publication history: Received on 21 November 2021; revised on 28 December 2021; accepted on 30 December 2021

Article DOI: https://doi.org/10.30574/wjarr.2022.13.1.0734

\begin{abstract}
Natural minerals are a powerful tool in politics when some have a major role in production. Its depletion is now a hot topic worldwide. Thus, the safety of the environment, natural surface water, groundwater and the protection of soils from chronic contamination by metallic and inorganic elements is a global concern. Indeed, industrialization and development have led to the generation of huge and varied amounts of waste, including electronic waste (e-waste), which is released into the environment. Although e-waste is classified as hazardous, most of it is not recycled and developed countries with strict environmental protection legislation send most of their e-waste to developing countries where regulations are lax. These electronic devices and components after being used are simply dumped into the environment due to lack of treatment and recycling strategy. As a result, they become a threat to the environment, ecosystems and humans. African countries are among the most vulnerable nations. But they are unfortunately ignored and underestimated. To date, there is no e-waste recycling unit (factory) in most African countries and mainly in the Republic of Benin. In response to this challenge, this study explored the different techniques used for the recycling of waste electrical/electronic equipment in order to develop a new environmentally friendly approach in future work, for the extraction and recycling of the usual and valuable metallic elements contained in electronic waste (printed circuit boards) released into the environment. For this purpose, a bibliographic research was carried out from 20 April to 16 October 2021. The results obtained allowed us to identify the advantages and disadvantages of existing recycling methods.
\end{abstract}

Keywords: Technology; Waste electrical and electronic equipment; Environment; Recycling; metals

\section{Introduction}

Nowadays, the world is producing more and more electrical and electronic waste. The consumption of electronic equipment is constantly increasing, because with the speed of technological progress, they become obsolete in a relatively short period of time $[1,2]$. According to $[3,4]$ the amount of computers, phones, televisions and devices being discarded doubled between 2009 and 2014, reaching 42 million tons per year worldwide. Developed countries, particularly in North America and Europe, generate the most e-waste. The United States generates more and China the second most [5]. It is therefore urgent to develop collection strategies for the recovery of this waste.

\footnotetext{
* Corresponding author: Yete Pélagie

Laboratory of Physical Chemistry-Materials and Molecular Modeling, Department of Chemistry, Faculty of Science and Technology, University of Abomey-Calavi, Abomey-Calavi, Benin.
}

Copyright (C) 2022 Author(s) retain the copyright of this article. This article is published under the terms of the Creative Commons Attribution Liscense 4.0. 
Indeed, the collection rates of waste electrical and electronic equipment (WEEE) vary greatly from country to country. Within the European Union, strong variations are observed: 15\% of WEEE is collected in Romania, while collection reaches $88 \%$ in Sweden [6]. In France, it was estimated at 45.2\% in 2016, which corresponds to the European average [7]. Numerous regulations have emerged, such as the 2012/19/EU directive which sets a target to be reached in 2020 of $85 \%$ collection of WEEE separately from household waste (European Union, 2012). The implementation of "Extended Producer Responsibility" (EPR) channels in France has strongly contributed to an improvement in collection [7]. Thus, 4.22 million tons of WEEE were collected between 2006 and 2016 including 0.73 million tons in 2016 alone. Local and global policies also have a role to play in encouraging recycling. In the European Union, some of the WEEE that is not collected would be mixed with household waste, which is mostly incinerated or landfilled. In developing countries, it is estimated that about $40 \%$ of WEEE is also landfilled [8].

Thus, the management of these products at the end of their life has three objectives: (i) the reduction of waste quantities by changing our consumption patterns and working on the repair of WEEE; (ii) the reuse of part of the components to insert them in new objects; (iii) the recycling of raw materials. For the latter, the efficient collection of waste and the development of new recycling processes must be established.

In order to meet these objectives, methods for recovering metals from waste materials have been proposed in the literature. This study therefore aims to highlight the different processes used for WEEE recycling. It has highlighted the advantages and limitations of the processes used.

\section{Methodology}

A literature review was conducted between April 2021 to October 2021. The research considered: e-waste management, printed circuit boards of electronic and electrical waste, precious metals. It extended back to 2003.

\section{Results}

\subsection{Waste electrical and electronic equipment: potential sources of base and precious metals}

At the end of its life, Electrical and Electronic Equipment (WEEE), becomes Waste or Electronic Waste. Each year, 20 to 50 million tons of WEEE are produced worldwide [9]. This volume is growing rapidly due to high renewal frequencies, usage patterns and technological innovation favouring rapid obsolescence [10].

According to $[3,4]$ confirmed that, the amount of computers, phones, televisions and devices being discarded doubled between 2009 and 2014 to 42 million tons per year worldwide. Developed countries, particularly in North America and Europe, generate the most e-waste. The United States generates the most and China the second most [5]. Although ewaste is classified as hazardous, most of it is not recycled, and rich countries with strict environmental protection legislation send most of their e-waste to developing countries with lax regulations [2]. Many of these poor countries, particularly in Africa, have little or no e-waste laws [2]. The e-waste legislation in Africa, India and China is ineffective and inconsistently enforced. These underpin the statement in [2] "International cooperation is needed to prevent developed countries from simply dumping obsolete electronic equipment on developing countries".

Furthermore, e-waste is a real source of metals (Table 1) and a source of serious environmental contamination, which requires special attention, lest there be an accumulation of pollutants in the environment, soil and surface water reservoir.

Table 1 below gives us the composition of metals in printed circuit boards. From the analysis of this table, it appears that printed circuit boards are the seat of metals.

In Africa in general and in the Republic of Benin in particular, these printed circuit boards are sources par excellence of serious environmental contamination in terms of metallic contaminants and the release of persistent organic pollutants into the environment. It is therefore urgent to think about their recycling. 
Table 1 Comparative wealth of metal ores and circuit boards [11].

\begin{tabular}{|c|c|c|}
\hline Resource & (pds) in the ores & \%(pds) in circuits prints \\
\hline $\mathrm{Cu}$ & $1.3 \%$ & $26.61 \%$ \\
\hline $\mathrm{Fe}$ & $42 \%$ & $1.08 \%$ \\
\hline $\mathrm{Al}$ & $42 \%$ & $0.58 \%$ \\
\hline $\mathrm{Pb}$ & $5.9 \%$ & $2.19 \%$ \\
\hline $\mathrm{Zn}$ & $4.2 \%$ & $2.03 \%$ \\
\hline $\mathrm{Nor}$ & $0.6 \%$ & $1.08 \%$ \\
\hline $\mathrm{Sn}$ & $0.86 \%$ & $3.21 \%$ \\
\hline $\mathrm{At}$ & $6.1 \mathrm{ppm}$ & $665 \mathrm{ppm}$ \\
\hline $\mathrm{Pt}$ & $2.9 \mathrm{ppm}$ & $37 \mathrm{ppm}$ \\
\hline $\mathrm{Pd}$ & & $48 \mathrm{ppm}$ \\
\hline $\mathrm{Ag}$ & $590 \mathrm{ppm}$ & $1700 \mathrm{ppm}$ \\
\hline $\mathrm{Plastic}$ & 0 & $32 \%$ \\
\hline Ceramic & - & $21 \%$ \\
\hline
\end{tabular}

Studies in [12] have shown that waste electrical and electronic equipment is very complex and varied. The composition of the waste varies according to the type of waste and its life span. Most of the metals found in electronic waste come from printed circuit boards (PCBs), which are elements that ensure the electrical connections between electronic components while serving as a support. Figure 1 below gives an overview of the elements in PCBs.

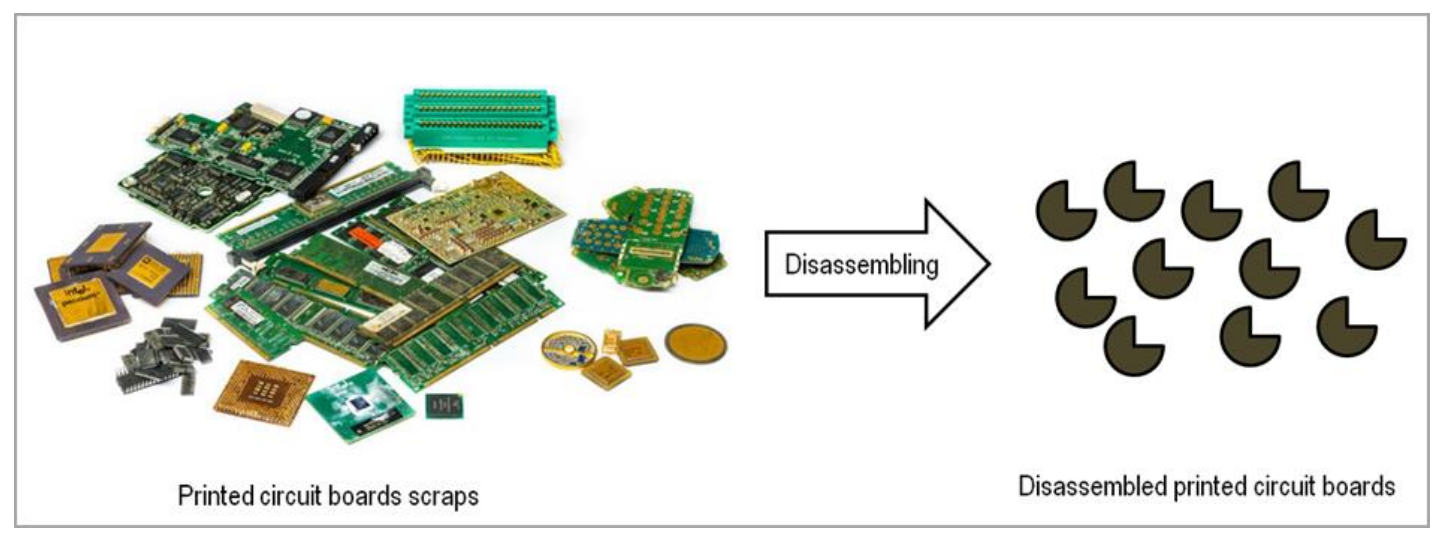

Figure 1 Pre-treatment and sorting of e-waste

Work [13] has shown that PCBs, due to their composition, are the constituents of electronic waste with the highest value and the greatest impact on our environment. The elemental composition of PCBs (nature of chemical elements and concentrations) depends on their date of manufacture, their origin and the electrical and electronic equipment from which these boards originate. In general, there are about 30\% plastics, $30 \%$ ceramics and glass and $40 \%$ metals [14]. Table 2 shows typical metal compositions in electronic boards [15, 16, 17].

Indeed, the metal contents of printed circuit boards are generally higher than those of primary raw material deposits, which shows the need to upgrade them. They can contain 20 to 40 times more copper and 20 to 250 times more gold than ores [12]. Furthermore, many metals or metalloids contained in printed circuit boards, such as antimony, tungsten, cobalt, germanium, gallium, indium or tantalum, are classified as critical substances by the European Union. 
Table 2 Typical metal composition in electronic boards

\begin{tabular}{|c|c|c|c|c|}
\hline & & [16] & [15] & [17] \\
\hline \multirow{6}{*}{ Base metal concentrations (in \% by mass) } & $\mathrm{Cu}$ & $20.00 \%$ & $14.20 \%$ & $11.00 \%$ \\
\hline & $\mathrm{Fe}$ & $10.00 \%$ & $3.08 \%$ & $12.00 \%$ \\
\hline & $\mathrm{Al}$ & $5.70 \%$ & - & $8.60 \%$ \\
\hline & $\mathrm{Zn}$ & $0.70 \%$ & $0.18 \%$ & $1.40 \%$ \\
\hline & $\mathrm{Sn}$ & $2.10 \%$ & $4.79 \%$ & $2.70 \%$ \\
\hline & $\mathrm{Pb}$ & $1.50 \%$ & $2.50 \%$ & $3 \%$ \\
\hline \multirow{4}{*}{ Precious metal concentrations (in mg.kg-1) } & $\mathrm{Ag}$ & 2500 & 317 & 220 \\
\hline & At & 400 & 142 & 20 \\
\hline & $\mathrm{Pd}$ & 600 & - & 12 \\
\hline & $\mathrm{Pt}$ & 22 & - & - \\
\hline \multirow{8}{*}{ Concentrations of other metals (mg.kg-1) } & $\mathrm{Cr}$ & 1400 & - & 212 \\
\hline & $\mathrm{Sb}$ & 3000 & 500 & 600 \\
\hline & Nor & 7000 & 4100 & 1100 \\
\hline & Co & 60 & - & - \\
\hline & $\mathrm{Mn}$ & 5500 & 81 & - \\
\hline & Mo & 280 & - & - \\
\hline & $\mathrm{Mg}$ & 2800 & - & - \\
\hline & Your & 180 & - & - \\
\hline
\end{tabular}

However, the recovery of PCB waste faces several challenges:

- the diversity of these wastes, in terms of size, shape, constituents and composition, as explained above;

- the presence of about 50 different elements, which implies difficulties in metal purification compared to primary ore concentrates, which often contain less than 20 elements in usually lower proportions[16] ;

- $\quad$ the strong interweaving of these different elements, in the form of alloys for example; this makes it possible to obtain physical and chemical properties that are particularly useful in new technologies;

- $\quad$ their dispersion through the waste.

The current economic value of electronic boards is mainly based on their precious metal content. Precious metals account for $70 \%$ to $90 \%$ of the value of printed circuit boards, although their concentration is less than $1 \%$ by weight $[18,19,20]$.

\subsection{Recycling methods}

As previously reported, waste is a real source of metals. Their management deserves special attention, lest there be an accumulation of pollutants in the environment, the soil, the surface water reservoir; which would finally weaken the ecosystem and human health. For this reason, several authors have developed techniques and means for the extraction and recycling of common and valuable metallic elements contained in electronic waste discharged into the environment.

Work [11] has shown that there are two main ways of recovering metallic materials from both primary and secondary resources. These are shown in Figure 2, where we note the pyrometallurgical route, based on thermal treatments, and the hydrometallurgical route, based on a metal solubilisation stage. 


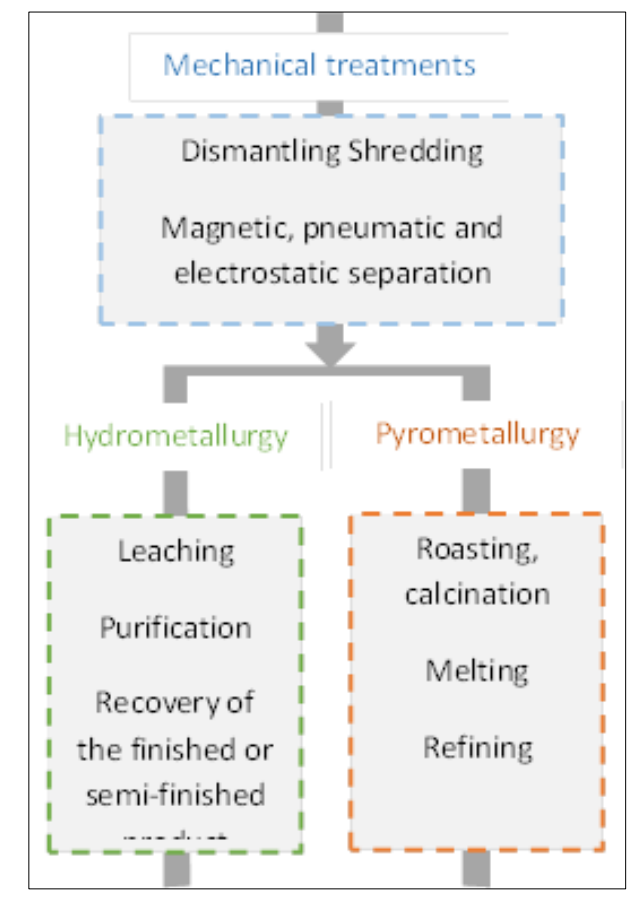

Figure 2 Classical routes of extractive metallurgy [11]

Other research has shown that a combination of methods is often used. These steps may be preceded by mechanical treatments to allow the elements to be concentrated in a particular fraction [21].

\subsubsection{Pyrometallurgy}

The pyrometallurgical technique is based on thermal treatments. Thermal energy is used to extract the metals in the waste. This operation includes several steps such as: pyrolysis, incineration, fusion.

This technique is the preferred treatment for the recovery of electronic boards [18]. This process uses a smelter that combines the primary ores of the electronic boards. Indeed, for the recovery of copper, this technique is generally used. It involves roasting, to eliminate certain undesirable elements such as plastics; smelting, to reach the liquid state of the elements to be recovered (temperature of about $1200^{\circ} \mathrm{C}$ ); transformation of the matte, obtained in the previous stage, into metallic copper by oxidation of the remaining sulphurous elements in a converter; and refining to purify the different elements [11]. Also, other steps can be added depending on the targeted metals.

Moreover, melting treatments are not the only pyrometallurgical treatments used. Various pyrolysis techniques have been developed for the pretreatment of waste [2,22, 23, 24]. Thus, pyrolysis makes it possible to break down the organic part into liquid or gaseous products, which can be reused as fuel. This makes it possible to limit the quantity of plastics present and to make the metals accessible so that they can then be solubilized. Another variant of this pre-treatment is incineration, which breaks down the organic matter into $\mathrm{CO} 2$ and $\mathrm{H} 20$ and releases the metals as oxides [25].

Further research is underway into the use of plasmast processing. In this process, the organic material is decomposed in the form of gas and the molten glass becomes glassy. It is then easy to separate the metals from the rest of the waste.

The use of molten salts, such as $\mathrm{KOH}-\mathrm{NaOH}$ or LiCl-KCl also allows the separation of metal products from the rest of the matrix that is molten, avoiding the oxidation of the metals of interest $[2,26]$. Thus a significant amount of $\mathrm{H} 2$ can be recovered. Finally, new vacuum metallurgy methods are also being developed [27, 28].

\subsubsection{The hydrometallurgical technique}

The hydrometallurgical process is one of the simplest ways to extract metals. This process involves leaching of PCBs residues by dissolving the metals with a suitable leaching solution, purifying the original leaching solution and recovering the metals by electrowinning [29]. Generally, the oxidative leaching process is required for efficient extraction of base and precious metals of interest. The dissolution step in the hydrometallurgical process, goes through the acid-base reaction, redox reaction or by redox reaction coupled with complexation reactions as well as on more or 
less complex purification steps so that the product, then shaped in a final step, finds its place in a specific market [12, 29]. Various leaching media have been studied such as nitric acid, hydrochloric acid, thiourea, cyanide, etc. [12, 18,]. [12, 18,]. This is a key step for hydrometallurgical processes: it must be fast, ideally selective to minimize the downstream purification steps and minimize the consumption of reagents, aggressive towards the material to be leached without being too corrosive for the equipment and generate a minimum of liquid, solid or gaseous effluents. All these conditions must allow the leaching operation to be easily integrated into the overall hydrometallurgical process in an efficient and cost-effective manner. Soft leaching operations should be favoured over high temperature, high pressure autoclave leaching processes which are energy and maintenance intensive. For example, the hydrometallurgical recovery of copper from metallic wastes is achieved by leaching in acids under oxidizing conditions [12, 30,] or in ammonia solutions [31, 32, 33]. Under optimal conditions, $90 \% \mathrm{Cu}, 60 \% \mathrm{Zn}$ and $9 \% \mathrm{Ni}$ could be dissolved from e-waste in $10 \mathrm{~h}$ with $99.97 \%$ copper purity that could be obtained in the electrowinning step.

Bioleaching is also used in mineral processing [34, 35, 36, 37]. It is an environmentally friendly and low-cost method. Currently, the application of bioleaching to recover metals from printed circuit board (PCB) waste has been reported [38]. For the recovery of precious metals from PCB waste, cyanogenic strains have been reported to be useful in the recovery of $\mathrm{Au}$ and Ag from PCB waste. Chromobacterium violaceum and Pseudomonas aeruginosa were the most reported strains [37, 39, 40]. According to [37] based on the optimized conditions, bioleaching using Pseudomonas chlororaphis, mixed $\mathrm{Au}$ and $\mathrm{Cu}$ particles could be simultaneously recovered up to $88.1 \mathrm{wt} \% \mathrm{Cu}$ and $76.6 \mathrm{wt} \% \mathrm{Au}$. However, this application is still in its infancy. The difficulty is how to separate the non-metallic parts when using the bioleaching method to recover metals from PCBs in industrial production. After dissolving the metal species contained in the ores or wastes, it is often necessary to carry out a filtration step in order to remove the refractory part that has not solubilized. The solid is a residue that can be recovered in other applications or stored as final waste. The solution containing the metals must then undergo a purification step that consists of selectively extracting the metals of interest. This purification step involves different technologies such as liquid-liquid extraction, solid-liquid extraction (with ion exchange resins or high surface area inorganic materials), or selective precipitation steps. The stream leaving the purification stage then undergoes further steps to produce a semi-finished or finished product in the form of a salt (crystallization or precipitation) or metal (electrolysis). The extraction of copper, cobalt, nickel and zinc from a leaching solution prepared from printed circuit boards can reach up to $99.99 \%$ when the leaching has been previously carried out in nitric or sulphuric media [24,41]. Currently, the most common method used for the extraction of gold and silver from ores is cyanidation $[29,42]$.This process could therefore be used for the extraction of metal from printed circuit boards [43].

\subsubsection{Biohydrometallurgy}

Biohydrometallurgy, the use of biotechnologies in extractive metallurgy, can be declined in different ways in terms of unit operations: bioleaching, bioextraction or even biodegradation of organic reagents [44]. The techniques for the recovery of metallic elements from electronic boards are therefore varied. They can be combined in different ways to recover all the elements of the electronic board. Figure 3 shows some combinations of techniques used to recover electronic boards, and in particular the metallic part contained in them.

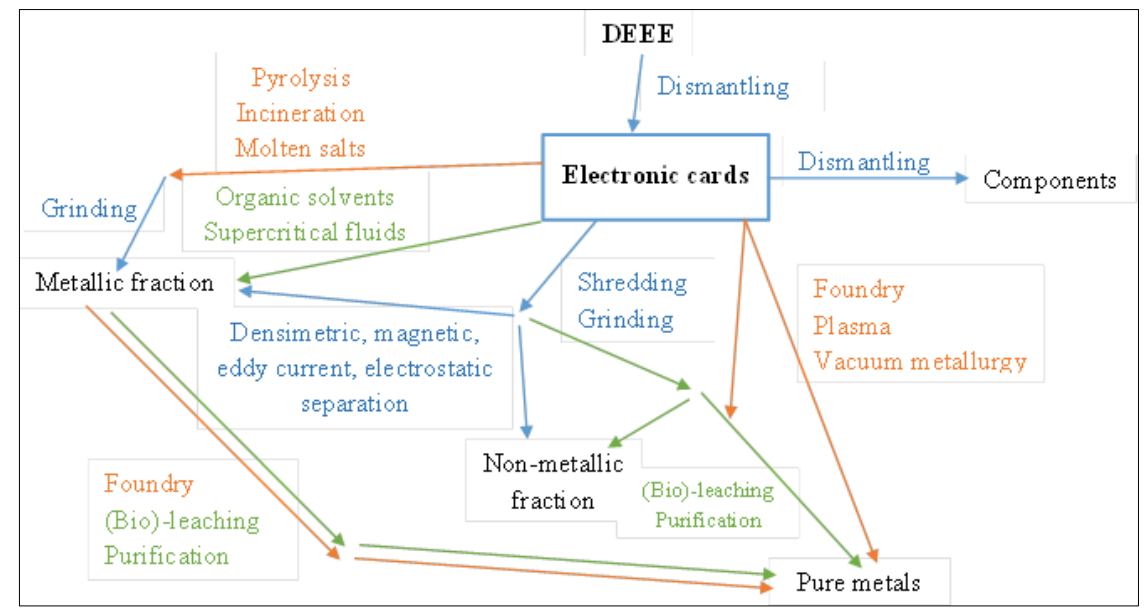

Figure 3 Examples of recycling routes for electronic boards (blue: mechanical treatments; green: hydrometallurgy; orange: pyrometallurgy). [11] 


\subsection{Advantages and disadvantages of recycling methods}

There are several advantages and disadvantages to using exciting techniques for recycling waste electrical and electronic equipment.

\subsubsection{Pyrometallurgy}

The physical methods used to treat e-waste [45], especially for PCB waste [46], were not able to recover all the metals present in the electrical and electronic waste. However, in corona-electrostatic separation, precious metals (Au or Ag), present in PCB waste in trace amounts, are omitted. In fact, the physical treatment presents an inability to recover precious metals. According to [19], commercial pyrometallurgy operations recover between 92 and $98 \%$ of the precious metals contained in the treated waste. Furthermore, operating costs can be reduced by using plastics as reducing agents in place of coke, as well as a source of energy [47]. Finally, the electronic boards do not need to undergo heavy mechanical treatments upstream to make the metals accessible. The energy cost of this technique limits its use to boards enriched with precious metals $[2,18]$.

However, despite the multiple advantages of this technique, other disadvantages are associated with these pyrometallurgical treatments. The works of are the evidence of this $[18,25,47]$. Among others, we can mention:

- $\quad$ PCBs can only represent about $10-15 \%$ of the incoming load, as shown in Table 5, in order to avoid the release of toxic gases resulting from the thermal decomposition of organic compounds. Therefore, in view of the capacities of the processing units currently in operation, only a small part of the electronic boards can be processed. These are only the rich boards.

- $\quad$ Energy demand is high;

- Aluminium and iron, as well as some strategic metals, are lost in the slag;

- Plastics cannot be recycled into other materials;

- $\quad$ Toxic gases and dusts are generated and cause additional costs.

\subsubsection{Hydrometallurgy}

Hydrometallurgy has advantages that make it a technology of choice for the coming decades according to the work of $[12,48]$. We will therefore retain:

- $\quad$ Production costs are reduced compared to pyrometallurgical processes (mainly related to energy expenses);

- $\quad$ Because of its low cost, hydrometallurgy allows the exploitation of poor or refractory ores, such as refractory gold ores. It could thus make it possible to upgrade poor electronic boards;

- Hydrometallurgy is suitable for the development of small treatment facilities because the investment costs are low compared to pyrometallurgical processes. Thus, a complete coverage of the territory can be envisaged, making it possible to limit the transport of waste to the recycling units;

- Hydrometallurgy appears to be a more flexible method in terms of the products processed: the process can be adapted to streams of varying composition;

- Hydrometallurgy is more selective than pyrometallurgy. It can therefore produce metals of higher purity. This is why these processes are sometimes used downstream of pyrometallurgical processes [18].

Nevertheless, the main difficulties with hydrometallurgical technology are its complexity, its hazardousness (safety risks) and the often observed low performance of quantitative oxidation of target metals. In addition, as environmental protection regulations become more stringent and the need to recycle e-waste increases, the fundamental research question is: "Which extraction solution should be used for the quantitative and reliable recovery of the valuable and common waste contained in e-waste? The problem with cyanidation is that it uses a highly toxic reagent, the process must be handled with care, and the disposal of the wastewater must be done with extreme rigor after the residue has been properly treated. Thus, the search for new and less toxic extraction solutions must be investigated.

\subsubsection{Biohydrometallurgy}

Biohydrometallurgy itself has advantages over hydrometallurgy [49]. As a result, the environment is generally less corrosive. Reagent requirements are lower, as they are produced in situ, which reduces costs and allows independence from the volatility of reagent prices. In addition, the temperatures are lower, so the energy demand is reduced. The treatment of ores and effluents can sometimes be done simultaneously.

On the other hand, this technique also has significant disadvantages. These include: 
- Toxicity of certain elements towards micro-organisms, which requires a period of adaptation to the environment in which they are used. This process is sometimes long and therefore makes them specific to the process. On complex and varied resources such as electronic boards, it can be complicated to stabilize the composition of the incoming solid flow to limit the effect on microorganisms.

- $\quad$ Residence times are generally longer.

- Acidophilic bioleaching requires large quantities of iron, which can interfere with the downstream metal recovery steps. In particular, the precipitation of Fe(III) during the purification steps following leaching leads to problems of co-precipitation of certain metals and the liquid-liquid extraction is often not very selective with respect to iron [50].

On the other hand, pyrometallurgical processes are validated and integrated, unlike biohydrometallurgy: the development of these new technologies represents a significant risk and financial investment, although reduced compared to pyrometallurgical processes. This represents an economic challenge, in addition to the technical challenges of understanding the phenomena.

\section{Conclusion}

This study allowed us to list the different techniques used for the recycling of waste electrical and electronic equipment, in particular PCBs (Printed Circuit Boards) on the one hand, and to identify the advantages and disadvantages of using these recycling methods on the other hand. Indeed, the non-metallic fraction in PCBs can be separated from the metallic fraction by physical separation, such as magnetic separation, flotation, electrostatic separation, hydrometallurgy and gravity separation. However, some challenges, such as how to achieve a clean and optimal separation between the nonmetallic and metallic fractions, remain with regard to the physical recycling of the non-metallic fraction.

Despite this, it is necessary to use mechanical treatments to prepare the material. In addition, large quantities of effluents must be treated and the solvents used in hydrometallurgy are sometimes toxic and can present risks for the environment.

They seem to give good results and do not always require mechanical pre-treatment, but these solutions are costly and can be accompanied by toxic discharges.

In addition, in view of the growth in global demand for metals, new processes must be developed to recover primary resources, the quality of which is declining, and secondary resources, the production of which is constantly increasing. In addition to contributing to the supply of metals, waste recycling also makes it possible to limit the environmental impact of landfilling or incineration.

Electronic boards are the part of WEEE that contains the most non-ferrous metals. Thus, there is a strong interest in recovering them. However, due to their composition and the quantity of metals present in these printed circuits, the recycling techniques developed are complex. On an industrial scale, pyrometallurgy is the only technique currently used. Despite good recovery rates for precious metals and copper, this technology has many environmental drawbacks. Moreover, it can only process a small proportion of the printed circuit board waste produced on a global scale. It therefore seems necessary to develop alternatives.

In general, these alternatives can be based on various combinations of techniques. Hydrometallurgy may have advantages in terms of lower capital and energy costs. Biohydrometallurgy, which is based on the use of microorganisms in extractive metallurgy, allows the in situ formation of reagents at limited costs and is being developed for the treatment of electronic boards. This method represents a possible technology for the recovery of waste, which must be inserted in a recycling chain, including a chain of upstream physical treatments to be implemented.

\section{Compliance with ethical standards}

\section{Acknowledgments}

The authors would like to thank the actors of this literature review, which initiates the work on waste electrical and electronic equipment. 


\section{Disclosure of conflict of interest}

The authors agree no conflict of interest.

\section{References}

[1] Petter PMH, Veit HM, Bernardes AM. Leaching of gold and silver from printed circuit board of mobile phones, REM: R. Esc. Minas, Ouro Preto. 2015; 68(1): 061-068.

[2] Wang Z, Zhang B, Guan D. Take responsibility for electronic-waste disposal. Nature. 2016; 536: 23.

[3] Robinson BH. An Assessment of Global Production and Environmental Impacts. Science of the Total Environment. 2009; 408: 183-191.

[4] Baldé CP. E-waste Statistics: Guidelines on Classifications, Reporting and Indicators. United Nations University, IAS-SCYCLE. 2015.

[5] Wang H, Zhang S, Li B, Pan D, Wu Y, Zuo T. Recovery of waste printed circuit boards through pyrometallurgical processing. A review, Resources, Conservation \& Recycling. 2017; 126: 209-218.

[6] Huisman J, Leroy P, Tertre F, Ljunggren Söderman M, Chancerel P, Cassard D, Løvik A N, Wäger P, Kushnir D, Rotter V S, Mählitz P, Herreras L, Emmerich J, Hallberg A, Habib H, Wagner M, Downes S. Prospecting Secondary Raw Materials in the Urban Mine and mining wastes (ProSUM). 2017; 48.

[7] Deloitte Développement Durable et Ademe, Deprouw A, Jover M, Chouvenc S, Fangeat E. Synthèse annuelle du registre des déchets d'équipements électriques et électroniques. 2017; 11.

[8] Bai J, Wang J, Xu J, Zhou M, Guan J, Zhang C. Microbiological recovering of metals from printed circuit boards by Acidithiobacillus ferrooxidans, Proceedings for the DEEE. International Symposium on Sustainable Systems and Technology. 2009

[9] UNEP. Recycling Rates of Metals - A status report, A report of the Working Group on the Global Metal Flows to the International Resource. 2011.

[10] Ogunniyi IO, Vermaak MKG, Groot DR. Chemical composition and liberation characterization of printed circuit board communition fines for beneficiation investigations, Waste Management. 2009; 29: 2140-2146.

[11] Agathe Hubau. Conception d'un procédé de biolixiviation pour la valorisation des métaux contenus dans les déchets de cartes électroniques. Université Paris sciences et lettres. 2019.

[12] Tuncuk A, Stazi V, Akcil A, Yazici EY, Deveci H. Aqueous metal recovery techniques from e-scrap: Hydrometallurgy in recycling. Minerals Engineering. 2012; 25: 28-37.

[13] Ning C, Lin CSK, Hui D, McKay G. Waste Printed Circuit Board (PCB) Recycling Techniques, Top. Curr. Chem (Z). 2017; 375: 43.

[14] Sum E. The recovery of metals from electronic scrap, Review of Extractive Metallurgy, JOM. 1991; 53-61.

[15] Bizzo WA, Figueiredo RA, de Andrade VF. Characterization of Printed Circuit Boards for Metal and Energy Recovery after Milling and Mechanical Separation. Materials. 2014; 7: 4555-4566.

[16] UNEP. Metal Recycling: Opportunities, Limits, Infrastructure, A Report of the Working Group on the Global Metal Flows to the International Resource. 2013.

[17] UNU. Final Report on the Review of Directive 2002/96 on Waste Electrical and Electronic Equipment (WEEE). 2008.

[18] Cui J, Zhang L. Metallurgical recovery of metals from electronic waste. A review, Journal of Hazardous Materials. 2008; 158: 228-256.

[19] Goosey M, Kellner R. Recycling technologies for the treatment of end of life printed circuit boards (PCBs). Circuit World. 2003; 29(3): 33-37.

[20] Park YJ , Fray DJ. Recovery of high purity precious metals from printed circuit boards, Journal of Hazardous Materials. 2009; 164: 1152-1158.

[21] Chagnes A, Cote G, Ekberg C, Nilsson M, Retegan T. DEEE Recycling, Research, Development and Policies, in Elsevier. 2016. 
[22] Bidini G, Fantozzi F, Bartocci P, D’Alessandro B, D’Amico M, Laranci P, Scozza E, Zagaroli M. Recovery of precious metals from scrap printed circuit boards through pyrolysis. Journal of Analytical and Applied Pyrolysis. 2015; 111: 140-147.

[23] Hall WJ, Williams PT. Separation and recovery of materials from scrap printed circuit boards. Resources, Conservation and Recycling. 2007; 51: 691-709.

[24] Kumari A, Jha M K, Lee J C, Singh R P. Clean process for recovery of metals and recycling of acid from the leach liquor of PCBs. Journal of Cleaner Production. 2016; 112: 4826-4834.

[25] Li J, Lopez, B N, Liu L, Zhao N, Yu, K, Zheng K. Regional or global WEEE recycling. Where to go? Waste Manage. 2013; 33: 923-934.

[26] Flandinet L, Tedjar F, Ghetta V, Fouletier J. Metals recovering from waste printed circuit boards (WPCBs) using molten salts. Journal of Hazardous Materials. 2012; 213-214: 485-490.

[27] Zhang L, Xu Z. A review of current progress of recycling technologies for metals from waste electrical and electronic equipment. Journal of Cleaner Production. 2016; 127: 19-36.

[28] Zhou YH, Wu WB, Qiu KQ. Recycling of organic materials and solder from waste printed circuit boards by vacuum pyrolysis-centrifugation coupling technology. Waste Manag. 2011; 31: 2569-2576.

[29] Rudnik E, Pierzynka M, Handzlik P. Ammoniacal leaching and recovery of copper from alloyed low-grade e-waste, J Mater Cycles Waste Manage. 2016; 18, 318-328.

[30] Birloaga I, De Michelis I, Ferella F, Buzatu M, Veglio F. Study on the influence of various factors in the hydrometallurgical processing of waste printed circuit boards for copper and gold recovery. Waste Management. 2013; 33: 935-941.

[31] Oishi T, Koyama K, Alam S, Tanaka M, Lee JC. Recovery of high purity copper cathode from printed circuit boards using ammoniacal sulfate or chloride solutions. Hydrometallurgy. 2007; 89: 82-88.

[32] Bari F, Begum N, Hamaludin S B, Hussin K. Selective leaching for the recovery of copper from PCB, proceedings of the Malaysian Metallurgical Conference ‘09, 1-1.12 2009; 1-4.

[33] Lim Y, Kwon O K, Lee J, Yoo K. The ammonia leaching of alloy produced from waste printed circuit boards smelting process. Geosys. Eng. 2013; 16, 216-224

[34] Veglio F, Beolchini F, Gasbarro A, Toro L, Ubaldini S, Abbruzzese C. Batch and semi-continuous tests in the bioleaching of manganiferous minerals by heterotrophic mixed microorganisms. International Journal ofMineral Processing. 1997; 50(4): 255-273.

[35] Watling H. The bioleaching of sulphide minerals with emphasis on copper sulphides-A review. Hydrometallurgy. 2006; 84: 81-108.

[36] Pant D, Joshi D, Upreti M K, Kotnala R K. Chemical and biological extraction of metals present in E waste: a hybrid technology. Waste Manage. 2012; 32: 979-990.

[37] Breivik K, Armitage J M, Wania F, Jones K C. Environ. Sci. Tech. 2014; 48: 8735-8743.

[38] Xiang Y, et al. Bioleaching of copper from waste printed circuit boards by bacterial consortium enriched from acid mine drainage. J. Hazard. Mater. 2010; 184: 812- 818.

[39] Chi T. Bioleaching of gold and copper from waste mobile phone PCBs by using a cyanogenic bacterium. Miner. Eng. 2011; 24: 1219-1222.

[40] Smith D, Spanel P, Gilchrist F, Lenney W. Hydrogen cyanide, a volatile biomarker of pseudomonas aeruginosa infection. Breath. Res. 2013; 7: 044001.

[41] Ghosh B, Ghosh M K, Parhi P, Mukherjee P S, Mishra B K. Waste Printed Circuit Boards recycling: an extensive assessment of current status, Journal of Cleaner Production. 2015; 94: 5-19.

[42] Chu CK, Breuer PL, Jeffrey MI. The impact of thiosulfate oxidation products on the oxidation of gold in ammonia thiosulfate solutions. Minerals Enᄀgineering. 2003; 16: 265-271.

[43] Eswaraiah C, Kavitha T, Vidyasagar S, Narayanan SS. Classification of metals and plastics from printed circuit boards (PCB) using air classifier, Chem Eng Process Process Intensif. 2008; 47: 565-576.

[44] Morin D. Biotechnologies dans la métallurgie extractive - Microbiologie et extraction des métaux. Techniques de l’Ingénieur. 2013; M2238 v3. 
[45] Ruan J, Xu Z. Approaches to improve separation efficiency of eddy current separation for recovering aluminum from waste toner cartridges. Environ. Sci. Technol. 2012a; 46: 6214- 6221.

[46] Veit HM, Diehl TR, Salami AP, Rodrigues JS, Bernardes AM, Tenório JAS. Utilization of magnetic and electrostatic separation in the recycling of printed circuit boards scrap. Waste Management. 2005; 25: 67-74.

[47] Hagelüken C. Recycling of Electronic Scrap at Umicore's Integrated Metals Smelter and Refinery. World of Metallurgy - Erzmetall. 2006; 59(3): 152-161.

[48] Brierley CL. Biohydrometallurgical prospects. Hydrometallurgy. 2010; 104: 324-328.

[49] Mrážiková A, Kaduková J, Marcinčáková R, Velgosová O, Willner J, Fornalczyk A, Saternus M. The effect of specific conditions on $\mathrm{Cu}, \mathrm{Ni}, \mathrm{Zn}$ and $\mathrm{Al}$ recovery from PCBs waste using acidophilic bacterial strains. Arch. Metall. Mater. 2016; 61(1): 261-264.

[50] Willner J, Fornalczyk A. Extraction of copper from solution after bioleaching of Printed Circuit Boards (PCBs). Metallurgical. 2015; 53(2): 228-230. 